\title{
TU/e EmonOWEN

\section{Assessment of the healing process in distal radius fractures by high resolution peripheral quantitative computed tomography}

Citation for published version (APA):

Jong, de, J. J. A., Willems, P. C., Arts, J. J. C., Bours, S. G. P., Brink, P. R. G., Geel, van, T. A. C. M., Poeze, M., Geusens, P. P., Rietbergen, van, B., \& Bergh, van den, J. P. W. (2014). Assessment of the healing process in distal radius fractures by high resolution peripheral quantitative computed tomography. Bone, 64, 65-74. https://doi.org/10.1016/j.bone.2014.03.043

DOI:

10.1016/j.bone.2014.03.043

Document status and date:

Published: 01/01/2014

\section{Document Version:}

Accepted manuscript including changes made at the peer-review stage

\section{Please check the document version of this publication:}

- A submitted manuscript is the version of the article upon submission and before peer-review. There can be important differences between the submitted version and the official published version of record. People interested in the research are advised to contact the author for the final version of the publication, or visit the $\mathrm{DOI}$ to the publisher's website.

- The final author version and the galley proof are versions of the publication after peer review.

- The final published version features the final layout of the paper including the volume, issue and page numbers.

Link to publication

\section{General rights}

Copyright and moral rights for the publications made accessible in the public portal are retained by the authors and/or other copyright owners and it is a condition of accessing publications that users recognise and abide by the legal requirements associated with these rights.

- Users may download and print one copy of any publication from the public portal for the purpose of private study or research.

- You may not further distribute the material or use it for any profit-making activity or commercial gain

- You may freely distribute the URL identifying the publication in the public portal.

If the publication is distributed under the terms of Article 25fa of the Dutch Copyright Act, indicated by the "Taverne" license above, please follow below link for the End User Agreement:

www.tue.nl/taverne

Take down policy

If you believe that this document breaches copyright please contact us at:

openaccess@tue.nl

providing details and we will investigate your claim. 
Original Full Length Article

\title{
Assessment of the healing process in distal radius fractures by high resolution peripheral quantitative computed tomography
}

\author{
Joost J.A. de Jong a,b,*, Paul C. Willems ${ }^{\text {c,d }}{ }^{\text {, Jacobus J. Arts }}{ }^{\mathrm{c}, \mathrm{d}}$, Sandrine G.P. Bours ${ }^{\mathrm{b}}$, Peter R.G. Brink ${ }^{\mathrm{e}}$, \\ Tineke A.C.M. van Geel ${ }^{\mathrm{d}, \mathrm{f}}$, Martijn Poeze ${ }^{\mathrm{a}, \mathrm{e}}$, Piet P. Geusens ${ }^{\mathrm{b}, \mathrm{d}, \mathrm{g}}$, \\ Bert van Rietbergen ${ }^{h}$, Joop P.W. van den Bergh ${ }^{\text {a,b,g,i }}$
}

a Research School NUTRIM, Maastricht University, The Netherlands

${ }^{\mathrm{b}}$ Department of Rheumatology, Maastricht University Medical Center, The Netherlands

c Department of Orthopedics, Maastricht University Medical Center, The Netherlands

${ }^{d}$ Research school CAPHRI, Maastricht University, The Netherlands

e Department of Surgery, Maastricht University Medical Center, The Netherlands

${ }^{\mathrm{f}}$ Department of General Practice, Maastricht University, The Netherlands

${ }^{g}$ Faculty of Medicine and Life Sciences, Hasselt University, Belgium

${ }^{\text {h }}$ Faculty of Biomedical Engineering, Eindhoven University of Technology, The Netherlands

i Department of Internal Medicine, Viecuri Medical Center Venlo, The Netherlands

\section{A R T I C L E I N F O}

\section{Article history:}

Received 11 July 2013

Revised 5 March 2014

Accepted 24 March 2014

Available online 2 April 2014

Edited by Michael Amling

\section{Keywords:}

Fracture healing

Distal radius

HR-pQCT

\begin{abstract}
A B S T R A C T
In clinical practice, fracture healing is evaluated by clinical judgment in combination with conventional radiography. Due to limited resolution, radiographs don't provide detailed information regarding the bone micro-architecture and bone strength. Recently, assessment of in vivo bone density, architectural and mechanical properties at the microscale became possible using high resolution peripheral quantitative computed tomography (HR-pQCT) in combination with micro finite element analysis ( $\mu$ FEA). So far, such techniques have been used mainly to study intact bone. The aim of this study was to explore whether these techniques can also be used to assess changes in bone density, micro-architecture and bone stiffness during fracture healing. Therefore, the fracture region in eighteen women, aged 50 years or older with a stable distal radius fracture, was scanned using HR-pQCT at 1-2 (baseline), 3-4, 6-8 and 12 weeks post-fracture. At 1-2 and 12 weeks post-fracture the distal radius at the contra-lateral side was also scanned as control. Standard bone density, micro-architectural and geometric parameters were calculated and bone stiffness in compression, torsion and bending was assessed using $\mu$ FEA. A linear mixed effect model with time post-fracture as fixed effect was used to detect significant ( $p$-value $\leq 0.05$ ) changes from baseline. Wrist pain and function were scored using the patient-rated wrist evaluation (PRWE) questionnaire. Correlations between the bone parameters and the PRWE score were calculated by Spearman's correlation coefficient. At the fracture site, total and trabecular bone density increased by $11 \%$ and $20 \%$, respectively, at 6-8 weeks, whereas cortical density was decreased by $4 \%$. Trabecular thickness increased by 23-31\% at 6-8 and 12 weeks and the intertrabecular area became blurred, indicating intertrabecular bone formation. Compared to baseline, calculated bone stiffness in compression, torsion and bending was increased by $31 \%$ after 12 weeks. A moderate negative correlation was found between the stiffness and the PRWE score. No changes were observed at the contra-lateral side. The results demonstrate that it is feasible to assess clinically relevant and significant longitudinal changes in bone density, micro-architecture and mechanical properties at the fracture region during the healing process of stable distal radius fractures using HR-pQCT.
\end{abstract}

(c) 2014 Elsevier Inc. All rights reserved.

\section{Introduction}

Fragility fractures of the distal radius are one of the most common fractures. The incidence is about $17 \%$ of all fractures [1]. Although not always acknowledged, the outcome of distal radius fractures is not uniformly good. Poor outcomes have been attributed to poor restoration

\footnotetext{
* Corresponding author at: Maastricht University Medical Center, Department of Rheumatology, P.O. Box 5800, 6202 AZ Maastricht, The Netherlands.

E-mail address: joost.dejong@maastrichtuniversity.nl (J.J.A. de Jong).
}

of anatomy and secondary loss of reduction after an initially adequate reduction [2], leading to discomfort, loss of range of motion and/or soft tissue complaints [3-5].

It is expected that the addition of medication or supplements, such as vitamin $D$ or calcium can improve the clinical outcome of distal radius fractures [6]. To monitor the process of fracture healing in patients, who either received supplemental medication or not, a method that is able to evaluate bone healing in detail is necessary. In clinical practice, fracture healing is evaluated by clinical judgment of the physician in combination with plain anteroposterior (AP) and lateral radiographs. However, 
these evaluations do not provide detailed information with regard to the healing process and consolidation of fractures on the level of cortical and trabecular bone micro-architecture.

Until recently, human bone micro-architecture could only be studied with bone biopsies, i.e. with 2D histomorphometry or 3D microCT, since imaging techniques that can provide sufficient resolution for bone structure in vivo were not available. Therefore, in vivo high resolution imaging studies on fracture healing were restricted to animals $[7,8]$. Classical QCT proved to be a successful estimator for the prediction of the mechanical stability of long bones [9], but was not sufficient to study fracture healing in the distal radius in patients because of insufficient resolution to visualize individual trabeculae [10].

With the development of a new low-dose radiation high resolution peripheral quantitative computed tomography (HR-pQCT) technique, i.e. XtremeCT, it is possible to assess in vivo bone density and architecture at the microscale [11-13]. Moreover, biomechanical properties of the bone can be calculated by micro finite element analysis ( $\mu \mathrm{FEA}$ ) based on such HR-pQCT images [11,14,15].

So far, these high resolution imaging techniques were mainly used to study micro-architectural changes due to aging [16,17], osteoporosis and other (bone) diseases $[15,18,19]$ and the effect of different treatments [20-23]. These techniques, however, could be applied as well to analyze the process of bone healing after a distal radius fracture. Potentially, such analyses could provide a new tool to assess fracture consolidation based on bone morphology or $\mu$ FEA derived mechanical parameters. In a recent study, Mueller et al. [24] investigated the feasibility of using these techniques to assess fracture healing in vivo and found an $18 \%$ increase in calculated stiffness over a period of 2 months. However, in that study biomaterials and plates were used to stabilize the fracture. The application of these techniques to fracture healing without any intervention, other than a standard cast, however, has not been demonstrated and it remains unclear to what extent the healing process can be captured by the standard morphological and mechanical parameters.

The objective of this study was, therefore, to explore the feasibility of HR-pQCT in combination with $\mu$ FEA to assess longitudinal changes in bone density, micro-architecture and biomechanical parameters during the first 12 weeks of healing of conservatively treated distal radius fractures.

\section{Materials and methods}

\section{Subjects}

Twenty women aged 50 years or older with a stable distal radius fracture, which was immobilized by a cast, were included in this study. All patients were included at the departments of Orthopedics and Traumatology of the Maastricht University Medical Center, the Netherlands. The exclusion criteria were: a history of previous fractures at the fractured side; known systemic or metabolic disorders leading to progressive bone deterioration; use of glucocorticoids; presence of an active inflammatory disease; presence of an active or suspected infection; or malignancy in the last 12 months pre-fracture.

To assess changes in bone density, micro-architecture, geometry and biomechanics, all patients underwent HR-pQCT scanning of the fractured distal radius during 4 visits. The visits were scheduled 1-2 weeks post-fracture (baseline) and 3-4 weeks, 6-8 weeks and 12 weeks post-fracture. During the first and last visit, the radius at the contra-lateral side was scanned as well. The protocol (registration no. NTR3821) was approved by an independent Medical Ethics Committee, and all patients gave written informed consent prior to participation.

\section{Scanning by HR-pQCT}

During each visit, the fractured radius was imaged by HR-pQCT (XtremeCT, Scanco Medical AG, Switzerland) using clinical in vivo settings by the manufacturer (effective energy of $60 \mathrm{kVp}$, tube current of $900 \mu \mathrm{A}$ and $100 \mathrm{~ms}$ integration time). The region of interest (Fig. 1) was based on AP and lateral radiographs of the fractured radius, in which the proximal edge of the lunate was used as reference. To make sure the complete fracture was scanned, the scan length was set to $18 \mathrm{~mm}$. With an isotropic voxel size of $82 \mu \mathrm{m}$, each HR-pQCT measurement thus resulted in 220 parallel CT slices. The effective dose of each HR-pQCT measurement at the fracture side was less than $6 \mu \mathrm{Sv}$. Because the patient's forearm was fixed in a cast, the forearm with the cast was placed in a custom cylindrical carbon holder with an inflatable cushion (Pearltec AG, Schlieren, Switzerland) to minimize patient motion. To scan the radius at the contra-lateral side, standard clinical in vivo settings by the manufacturer were used and resulted in one stack containing 110 parallel CT slices with an isotropic voxel size of $82 \mu \mathrm{m}$. The offset at the contra-lateral side was fixed for all patients and was chosen $9.5 \mathrm{~mm}$ from the proximal edge of the lunate. The volume between 9.5 and $18.5 \mathrm{~mm}$ from the lunate was thus scanned at the contralateral side. The same holder as for the fractured forearm was used to fix the contra-lateral side.

Each scan was checked for motion-induced image artifacts and was quality graded by the operator according to the manufacturer's guidelines and as described by Pialat et al. [25]. In case such artifacts occurred and thus resulted in images of insufficient quality, i.e. grade 4 or 5 , the scan was repeated.

\section{Evaluation of bone density, micro-architecture and geometry}

The HR-pQCT images were evaluated using the standard patient evaluation protocol provided by the manufacturer, which has been described earlier in detail [26]. In short, the cortical and trabecular regions were separated first using a semi-automated contouring scheme in which the periosteal boundary surface of the radius was derived [27]. After contouring, a Laplace-Hamming filter (epsilon 0.5 and cut-off frequency 0.4 ) followed by normalization (range 0-1000) and global thresholding (threshold 400), was used in order to extract the voxels that represented mineralized bone and to create the segmented images. The used values were default values specified by the manufacturer and these are consistently used for all HR-pQCT scanners.

The following bone density parameters were calculated from the images: volumetric bone mineral density $\left[\mathrm{mgHA} / \mathrm{cm}^{3}\right]$ was assessed for the total region (Dtot) and the trabecular (Dtrab) and cortical region (Dcort) separately.

The micro-architectural parameters that were used in this study were: the trabecular number (Tb.N) $[1 / \mathrm{mm}]$, thickness (Tb.Th) $[\mu \mathrm{m}]$ and separation (Tb.Sp) $[\mu \mathrm{m}]$, which are all determined using a 3D ridge extraction method [28] and standard morphological relations. Bone geometry was expressed by the cortical thickness (Ct.Th) [mm], which is calculated by dividing the cortical volume by the outer cortical surface, and the cortical perimeter (Ct.Pm) [mm], which is the average outer perimeter of the cortex.

\section{$\mu F E$ analysis}

With the standard approach for $\mu \mathrm{FE}$ analyses as used in most earlier studies, segmented images are used to create a representative $\mu \mathrm{FE}$ model of the bone's micro-architecture by converting each voxel that represents bone tissue into a brick element of the same size. Material properties then are chosen constant for all bone tissue [16], or varied only between cortical and trabecular bone tissue [15]. Whereas this approach has been well validated and successfully applied in clinical studies, its application to fractured bone is not trivial. The use of segmented images clearly limits the models to only represent the mineralized phase. In particular in the early stages of fracture healing this approach is expected to be inaccurate because it does not account for newly formed low mineralized bone. In an earlier study, Shefelbine et al. [8] therefore introduced a more sophisticated approach that can 

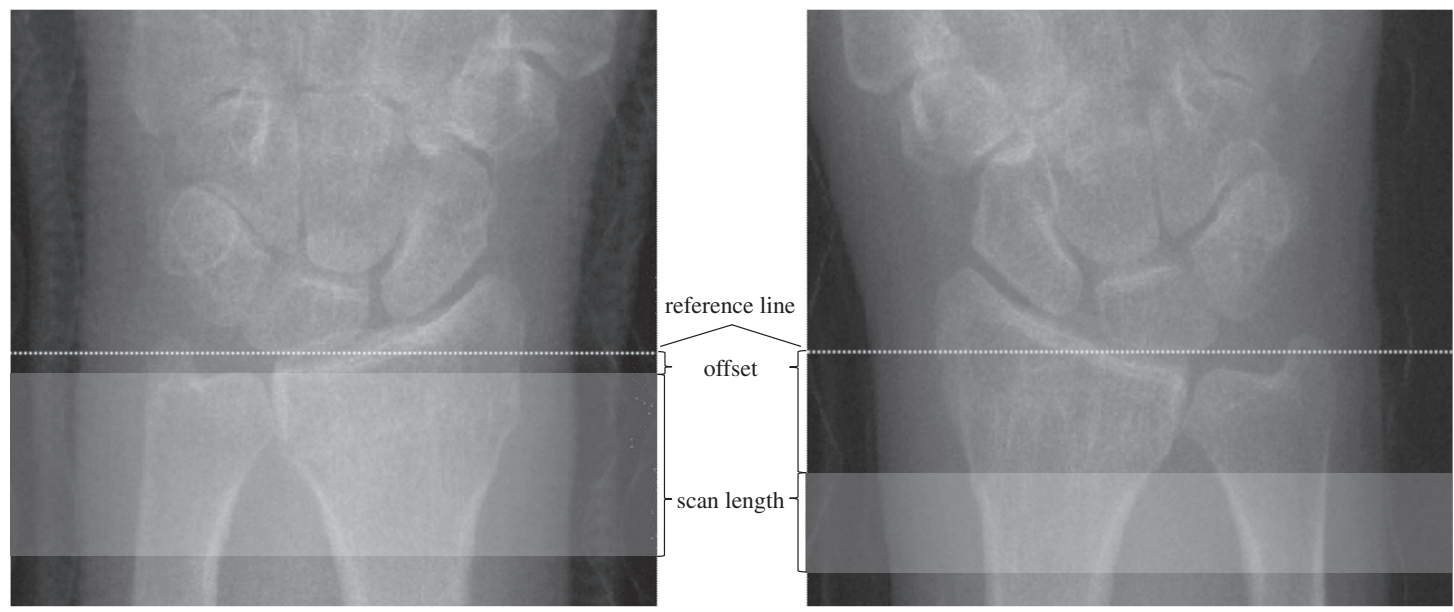

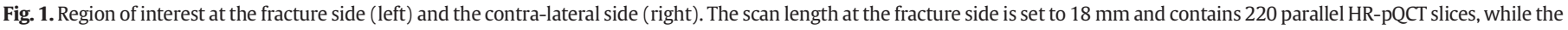

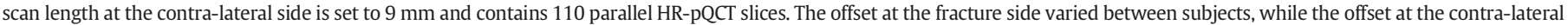
side was kept constant at a distance of $9.5 \mathrm{~mm}$ from the proximal edge of the lunate.

account for the stiffness of less mineralized tissues as well. With their approach, three different tissue types are distinguished (soft tissue, low mineralized tissue and high mineralized tissue) and the stiffness of the elements representing the mineralized tissue was made dependent on its material composition.

In the present study, we applied both the standard approach, which is validated for intact bone, and the approach proposed by Shefelbine et al.; [8], which is validated for healing bone. Since the method of Shefelbine et al. was originally developed for microCT data with a higher resolution, it was slightly adapted to apply it to the HR-pQCT data used in this study. In short, the grayscale bone density images were thresholded to define three separate regions: soft tissue, newly mineralized bone that had less mineral content, and highly mineralized bone using thresholds of 0-4000, 4001-5750 and 5751-max. (2-byte signed short-integer values, equal to $<343,343-642$ and $>642 \mathrm{mgHA} / \mathrm{cm}^{3}$ ), respectively. Elastic moduli were assigned to each region in agreement with Shefelbine et al.: $50 \mathrm{MPa}$ for soft tissue, $5000 \mathrm{MPa}$ for the newly mineralized bone, and $15000 \mathrm{MPa}$ for highly mineralized bone. Following, the model was downscaled by a factor 2 and each downscaled voxel was converted into a brick element, such that the final element size was $164 \mu \mathrm{m}$, which is similar to the element size used in the study by Shefelbine et al. ( $200 \mu \mathrm{m})$. In the resulting $\mu \mathrm{FE}$ model soft tissue was assigned a constant modulus of $50 \mathrm{MPa}$ whereas for mineralized bone a Young's modulus ranging from 5000 to 15000 MPa results, depending on the material composition of the downscaled voxel (Fig. 2). A Poisson's ratio of 0.3 was assigned to all elements and all materials were assumed to be linear elastic and isotropic.

With the standard $\mu \mathrm{FE}$ approach, a procedure similar to that described in earlier studies was used and all elements were assigned a Young's modulus of $10 \mathrm{GPa}$ and a Poissons ratio of $0.3[16,29,30]$.

By subsequently applying different load cases, clinically relevant loading scenarios were simulated and the associated stiffness was

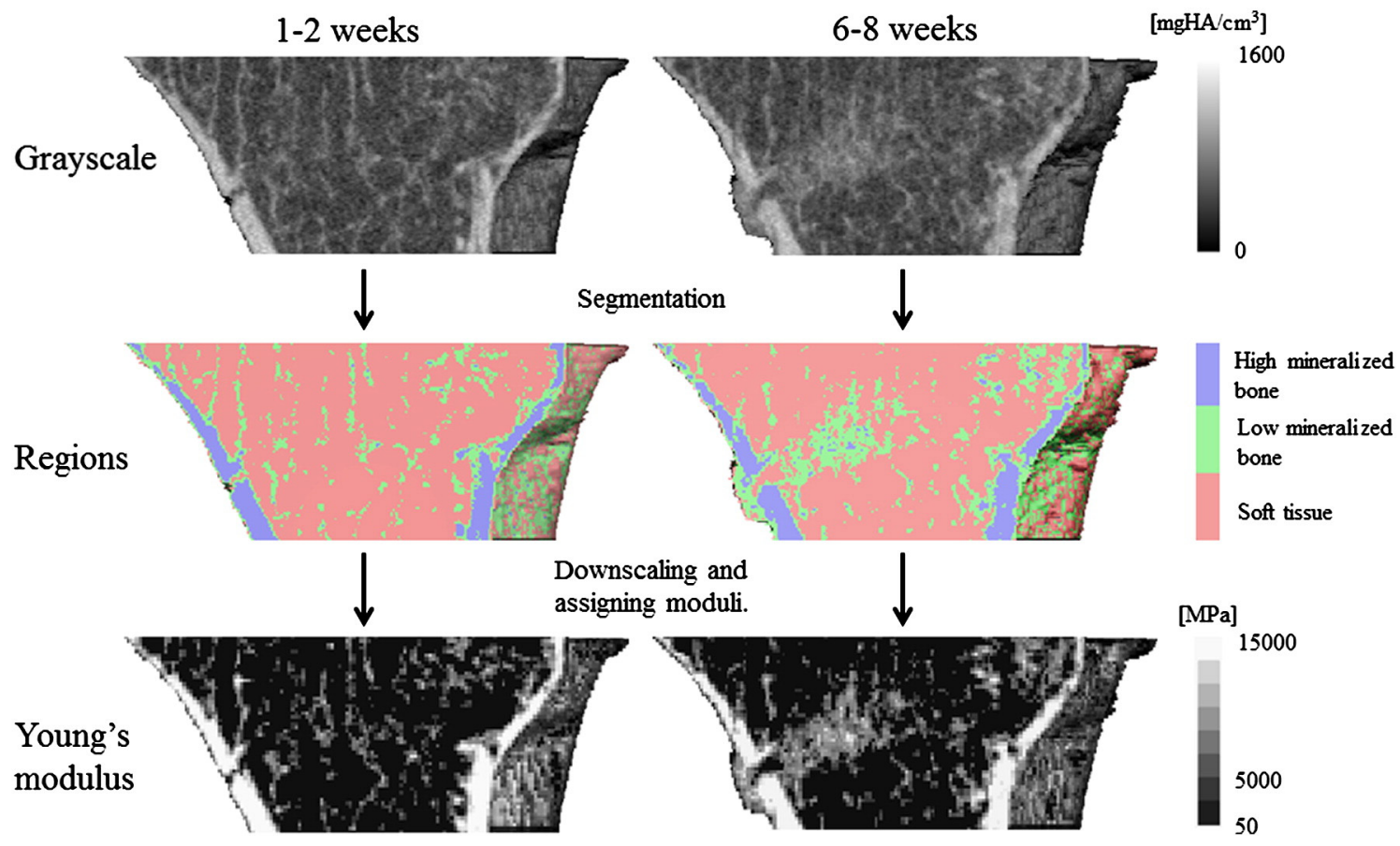

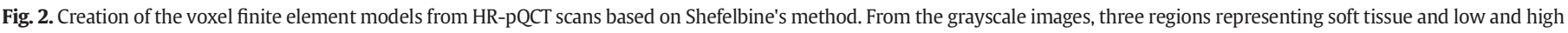

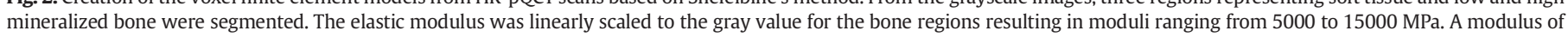
$50 \mathrm{MPa}$ was assigned to all soft tissue. (Left: $1-2$ weeks post-fracture, right: 6-8 weeks post-fracture). 
chosen as outcome variable. The first load case represented a 'high friction' compression test with a prescribed displacement in the axial direction of $1 \%$ of the total length, from which the compression stiffness (Scomp) $[\mathrm{kN} / \mathrm{mm}]$ was calculated. The second load case represented a prescribed rotation of $0.01 \mathrm{rad}$ around the longitudinal axis applied to the surface perpendicular to this axis from which the torsional stiffness (Stors) $[\mathrm{kNmm} / \mathrm{rad}]$ was calculated. A third and fourth load case represented a prescribed rotation of 0.01 rad applied around the sagittal and transversal axes respectively, onto the surfaces perpendicular to each axis, thus inducing a state of pure bending in two directions, from which the bending stiffness in each direction (S.sagittal and S.transversal) was calculated. Because the orientation of the patients' forearm was not exactly the same during all visits, a quadratic mean bending stiffness was calculated (Sbend) [ $\mathrm{kNmm} / \mathrm{rad}]$ from the sagittal and transversal bending stiffness according to Eq. (1).

Sbend $=\operatorname{sqrt}\left(0.5\left(\right.\right.$ S.sagittal $^{2}+$ S.transversal $\left.\left.^{2}\right)\right)$

\section{Clinical and radiological outcomes}

Pain and function were measured using a validated Dutch version of the Patient-Rated Wrist Evaluation (PRWE) questionnaire. The PRWE questionnaire consists of 10 questions and its score ranges from 0 (no pain/no difficulty) to 100 (worst pain/disability). It has previously been shown that PRWE is a reliable and valid measurement tool after distal radius fractures [31,32].

Based on AP and lateral radiographic images of the fractures, the state of consolidation was assessed at each visit by an experienced orthopedic surgeon. The state of consolidation was defined as none when there was no sign of cortical bridging or increased radio density along the fracture line; as incomplete when there was increased radio density along the fracture line and starting cortical bridging was observed; and as complete when fading of the initial fracture line was seen in combination with cortical bridging [33].

\section{Statistics}

The Shapiro-Wilk test was used to test if the bone parameters were normally distributed at all visits. Non-normally distributed parameters were log-transformed. Then, a linear mixed effect model with the time post-fracture as fixed effect was used to test if the bone parameters at the follow-up visits were significantly different from baseline. The bone density, architectural and mechanical parameters were expressed as estimated marginal means with $95 \%$ confidence intervals at each visit. Percent change from baseline in each parameter was calculated by dividing the difference from baseline by the mean value at baseline. Spearman's correlation coefficient was used to measure the correlation between the bone parameters and the clinical and radiological outcome. Statistical analyses were performed with SPSS Statistics for Windows version 20.0 (IBM Corp., Armonk, USA).

\section{Results}

From the 20 patients who were initially included in the study, one patient declined participation at the first visit and another patient at the second visit. Their results were not included in this study. The characteristics of the remaining 18 patients are presented in Table 1.

From the scans in the 18 patients, 40 out of a total of 108 scans ( $37 \%$ ) were initially of insufficient quality due to motion artifacts: 30 out of 72 scans at the fracture side and 10 out of 36 at the contra-lateral side. After repeating these scans, still $19 \%$ of the scans were of insufficient quality due to motion-induced image artifacts. These scans were not included in the analyses, thus in total 87 scans were used for the evaluation of the bone parameters (Fig. 3).
Table 1

Descriptive baseline characteristics of the 18 women that completed all study visits.

\begin{tabular}{ll}
\hline & $\begin{array}{l}\text { Mean } \pm \text { Std. dev. } \\
(\mathrm{n}=18)\end{array}$ \\
\hline Age [years] & $64 \pm 8$ \\
Weight [kg] & $70 \pm 8$ \\
BMI [kg/m2] & $27 \pm 4$ \\
Time since menopause [years] & $13 \pm 9$ \\
T-score total hip [-] & $-1.4 \pm 1.1$ \\
T-score lumbar spine [-] & $-2.4 \pm 1.5$ \\
25(OH)D level [nmol/L] & $63 \pm 29$ \\
25(OH)D level $<50 \mathrm{nmol} / \mathrm{L}[\mathrm{n}]$ & $7(39 \%)$
\end{tabular}

\section{Visual assessment}

The sequential HR-pQCT images showed a common pattern at the fracture region over time (Fig. 4). In general, the fracture line was clearly visible at 1-2 weeks post-fracture: the cortex was disrupted on several locations and the trabeculae along the fracture line were disrupted. At 3-4 weeks post-fracture, the trabecular region became blurred, i.e. the individual trabeculae were hard to distinguish. This blurring in the trabecular region was more pronounced at $6-8$ weeks post-fracture and decreased at 12 weeks post-fracture. Bridging of the cortex started at 6-8 weeks post-fracture and was completed at 12 weeks post-fracture. No changes were observed at the contra-lateral side.

\section{Quantitative assessment}

Estimated marginal means, 95\% confidence intervals and percent change from baseline for the bone parameters measured at the fractured side as well as the contra-lateral side are given in Table 2. Time series line-plots of the average percent change from baseline in the bone parameters are shown in Fig. 5.

At the fracture side, total bone density increased by $10.5 \%$ ( $p>0.01)$ at $6-8$ weeks post-fracture and showed a final change of $+9.1 \%$ $(p>0.05)$ at 12 weeks post-fracture (Fig. 5A). This was the result of cumulative, opposite changes in trabecular and cortical bone density. Whereas trabecular bone density (Fig. 5B) significantly increased to a peak of $20.4 \%(p<0.01)$ at $6-8$ weeks post-fracture and a final increase of $12.1 \%$ ( $p>0.05$ ) at 12 weeks post-fracture, cortical density decreased progressively to $-5.2 \%(p>0.05)$ at 12 weeks post-fracture (Fig. $5 \mathrm{C}$ ).

Trabecular thickness significantly increased by $23.0 \%(\mathrm{p}<0.01)$ after 6-8 weeks up to $30.5 \%(\mathrm{p}<0.01)$ at 12 weeks post-fracture (Fig. 5E). Trabecular number remained constant until 3-4 weeks post-fracture and subsequently tended to decrease by $14.8 \%(\mathrm{p}>0.05)$ at 12 weeks post-fracture (Fig. 5D). No significant changes were observed in trabecular separation (Fig. 5F).

There were no significant changes in cortical thickness (Fig. 5G) and cortical perimeter during the 12 weeks post-fracture (Fig. $5 \mathrm{H}$ ).

Bone stiffness in compression, torsion and bending calculated by the approach of Shefelbine et al. [8] (Figs. 5I, J and H, respectively) showed no significant change until 12 weeks post-fracture. At that time-point they were increased by $31.3 \%, 31.5 \%$ and $31.3 \%$ (all p $<0.01$ ), respectively. Bone stiffness in compression, torsion and bending calculated by the standard approach (data not shown in Table) showed a similar behavior, but were increased by $38.4 \%, 46.8 \%$ and $43.0 \%$ (all $\mathrm{p}<0.02$ ), respectively.

At the contra-lateral side, no significant changes from baseline were observed in any of the bone parameters.

\section{Correlation with clinical and radiological outcome}

PRWE score correlated significantly with trabecular thickness (rho $=-0.43, \mathrm{p}=0.001$ ) and stiffness in compression (rho $=-0.28$, $\mathrm{p}=0.029$ ), torsion ( $\mathrm{rho}=-0.29, \mathrm{p}=0.024$ ) and bending 


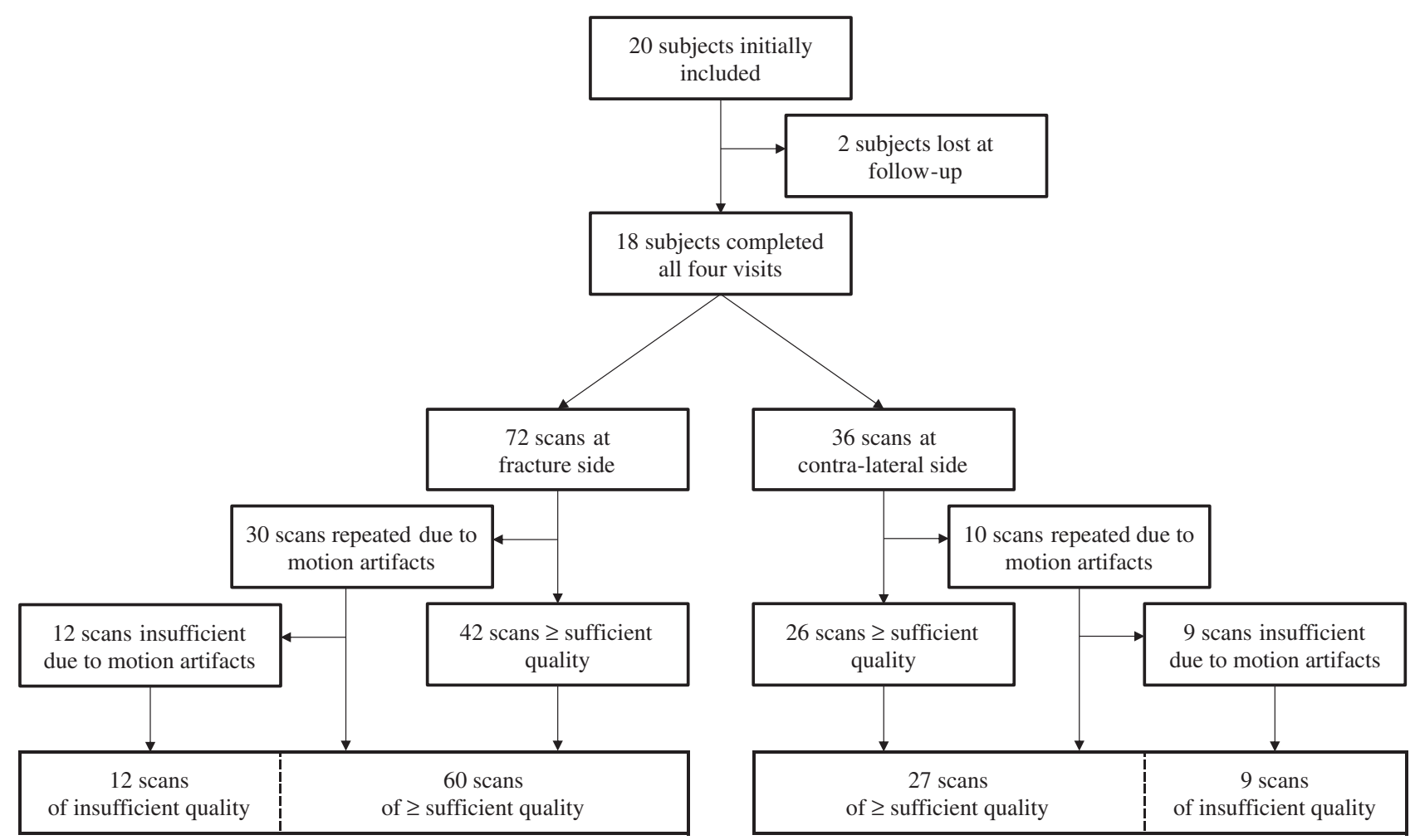

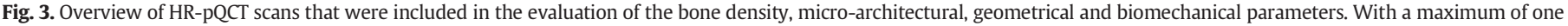
repeated measurement in case motion artifacts occurred, $83 \%$ of the scans at the fracture side and $75 \%$ of the scans at the contra-lateral side were finally of sufficient quality.

(rho $=-0.30, \mathrm{p}=0.019$ ) as calculated by Shefelbine's approach (Table 3). Similar correlations were found for the stiffnesses calculated with the standard $\mu \mathrm{FEA}$ approach: compression stiffness (rho $=-0.33$, $\mathrm{p}=0.011$ ), torsional stiffness ( $\mathrm{rho}=-0.32, \mathrm{p}=0.012$ ), and bending stiffness ( $r$ o $=-0.37, \mathrm{p}=0.004$ ) (Table 3 ).

The radiological state of consolidation correlated significantly with trabecular thickness ( rho $=0.35, \mathrm{p}=0.006$ ), cortical perimeter (rho $=-0.41, \mathrm{p}=0.001)$ and stiffness in compression ( rho $=0.44$, $\mathrm{p}<0.001$ ), torsion (rho $=0.35, \mathrm{p}=0.006$ ) and bending $(0.37, \mathrm{p}=$ 0.004 ) as calculated by Shefelbine's approach (Table 3). Using the standard $\mu \mathrm{FEA}$ approach, similar correlations were obtained: compression stiffness (rho $=0.50, \mathrm{p}<0.001$ ), torsional stiffness ( rho $=0.44$, $\mathrm{p}<0.001$ ), and bending stiffness (rho $=0.41, \mathrm{p}=0.001$ ) (Table 3 ).

No correlations were found between the other bone parameters and the PRWE score or the radiological state of consolidation.

Because the stiffness at the first visit is probably overestimated, we also calculated the correlation not taking the first visit into account. Then, the correlations between the PRWE score and the stiffness in compression, torsion and bending as calculated by Shefelbine's approach increase to $-0.37(\mathrm{p}=0.012),-0.40(\mathrm{p}=0.006)$ and -0.40 $(p=0.007)$, respectively. And the correlations between the PRWE score and the stiffnessess calculated by standard $\mu$ FEA approach increase to $-0.44(p=0.002),-0.35(p=0.017)$ and $-0.38(p=0.009)$ for the stiffness in compression, torsion and bending, respectively.

\section{Discussion}

The main objective of this study was to explore the feasibility of HR-pQCT based techniques to study the fracture healing process of conservatively treated distal radius fractures in vivo. The results show that it is possible to detect significant changes in HR-pQCT derived bone densitometric, micro-architectural and mechanical parameters during the first 12 weeks of fracture healing using HR-pQCT in combination with $\mu$ FEA. These results were obtained by performing the standard patient evaluation protocols that have been provided by the manufacturer and are readily available on every XtremeCT device. Although the contouring of the periosteal boundary often required manual correction due to the disruptions in the cortical surface, the calculation of the bone density and micro-architectural parameters could proceed in the standard way. Also the segmented 3D models could be used in the standard $\mu \mathrm{FEA}$ without problems.

The time-related increase in trabecular bone density with a peak at 6-8 weeks post-fracture was the most striking finding. At the timepoint of this peak increase, trabecular density was significantly increased and the trabecular structure, when visually assessed, became blurred (Fig. 4). This finding might reflect the formation of new woven bone between the trabeculae during early stages of distal radius fracture healing, which is supported by the histological findings reported by Aspenberg et al. [34]. At 12 weeks post-fracture, when the change from baseline in trabecular density was not significantly increased anymore, trabecular thickness further increased and the largest increase in calculated stiffness was observed. We hypothesize that the formation of new woven bone in the trabecular region in the first weeks postfracture is followed by extensive remodeling between weeks 6 and 12, when poorly mineralized unorganized woven bone is removed and replaced by normal well-organized bone tissue, with improved bone strength but a decrease of trabecular density at 12 weeks compared to 6 weeks post-fracture $[35,36]$. A similar process, where the increase in bone density precedes the micro-architectural adaptation, has been described in developing bone [37].

Although we do detect significant changes in structural parameters, the interpretation of these changes in the healing bone might not be the same as in intact bone and warrants additional discussion. The presence of woven bone at 3-4 and 6-8 weeks post-fracture, i.e. when the images show a more blurred region, influences the calculation of several parameters that are used to quantify the trabecular structure. With the standard evaluation used here, the trabecular thickness and separation are derived from trabecular bone density, via bone volume fraction, 

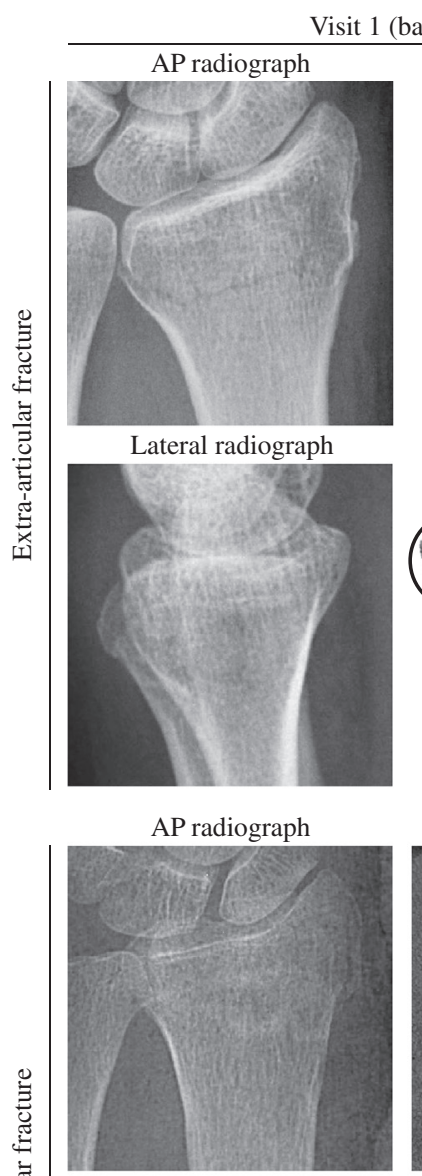

Lateral radiograph

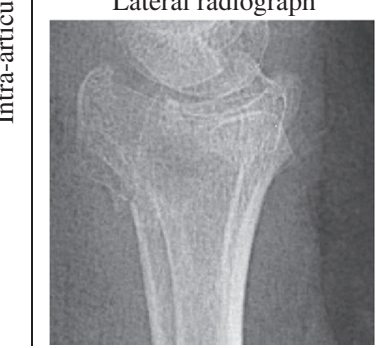

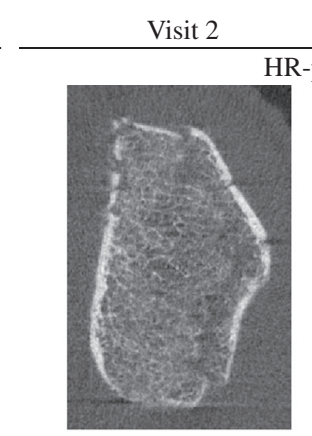

QCT slices
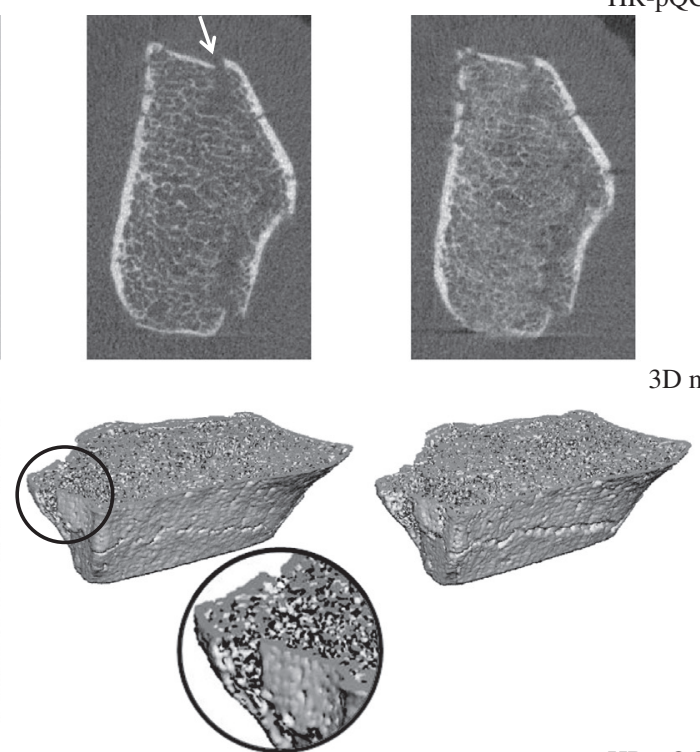

3D models

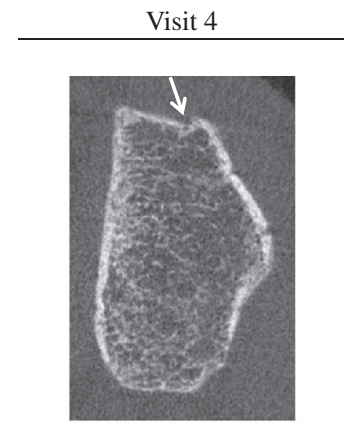

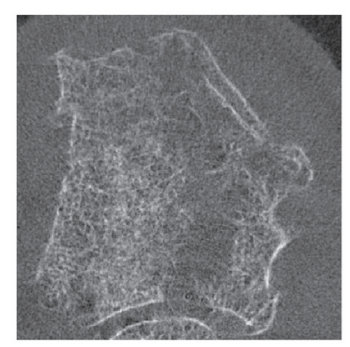

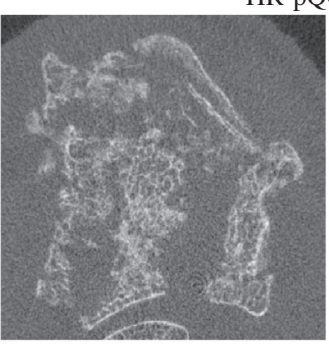

3D models
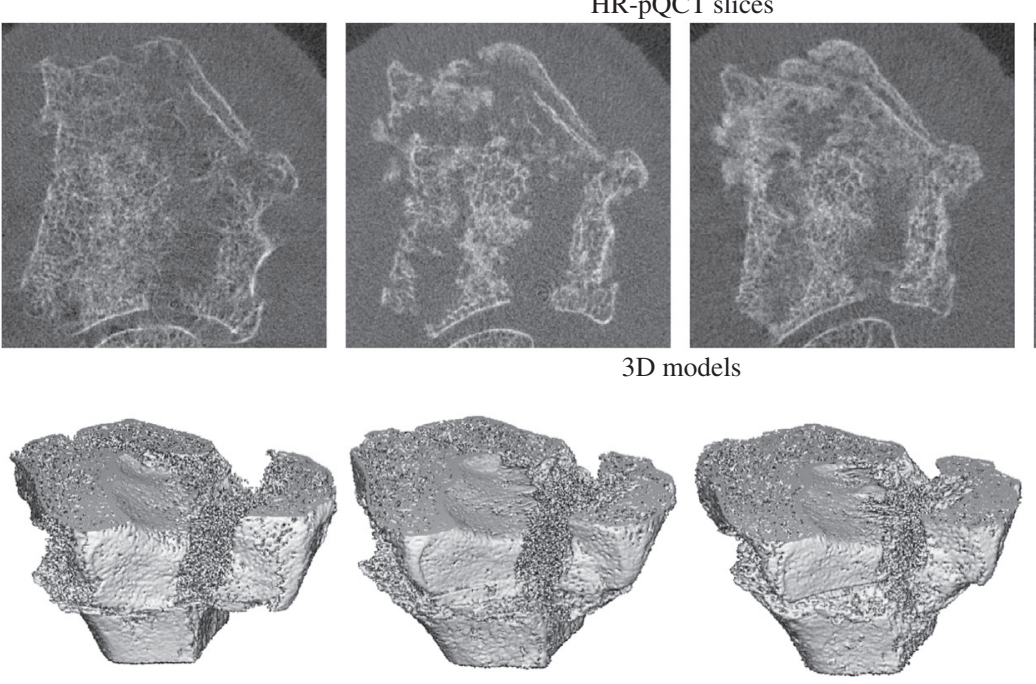
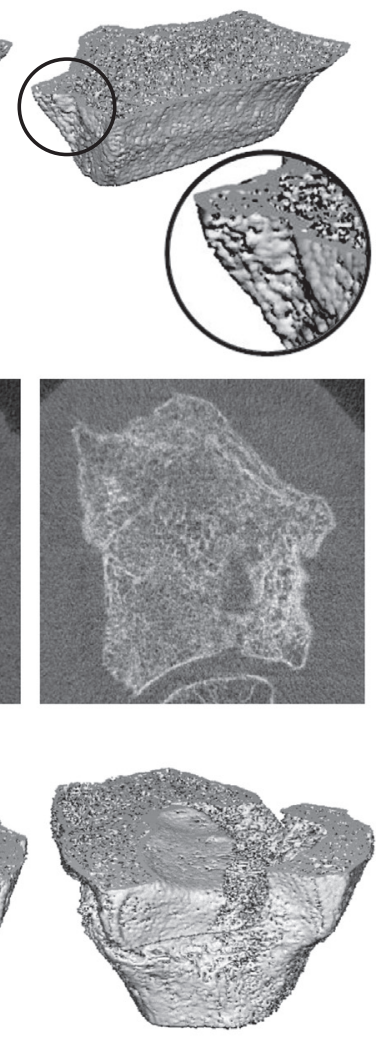

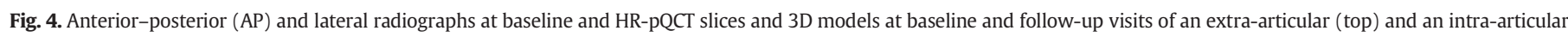

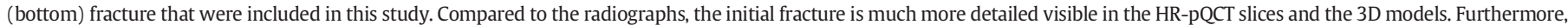
the increase in density in the trabecular region as well as the bridging of the cortex (arrows) is very well visualized in the HR-pQCT slices and 3D models (zoom-in).

and trabecular number according to standard histomorphometric relations [26]. Because of its finer structure and lower density not all woven bone is segmented after thresholding and, consequently, not included in the calculation of the trabecular number. It does, however, increase trabecular bone density. These combined effects lead to a significant increase in the calculated trabecular thickness parameter that, however, does not reflect an actual increase of the thickness of the trabeculae. This shows that one must take care with the interpretation of the structural parameters as they could represent a different morphological aspect in fractured bone than in intact bone. A second point that should be mentioned here is that the morphological parameters represent the average values for the whole analyzed region. The measured changes in bone morphology parameters thus are dependent on the size of the analyzed region and that of the fracture: if the fracture comprises a small part of the analyzed volume, changes in morphology parameters will appear to be smaller than in the case where the fracture occupies larger regions. The $\mu$ FEA parameters, however, are less sensitive to the size of the analyzed region and that of the fracture: even a small fracture can dramatically reduce the stiffness of the bone.
Despite the fact that the images also showed large local changes in the cortical region during the healing process, i.e. bridging of the cortex, the changes measured in cortical thickness were not significant. The calculation of cortical thickness, however, is the average of the whole cortical region and appears to be insensitive to these local changes. This finding suggests that a more localized approach is needed to describe the healing process in the cortical compartment.

\section{Restoration of bone stiffness}

Restoration of bone strength and stiffness is of particular interest during the healing process of fractures. Although the approach by Shefelbine et al. that was used in the finite element analysis was only validated for femoral fractures in rats [8], it is currently the only validated method reported in literature to assess the fracture stiffness in healing calluses through high resolution $\mathrm{CT}$, taking the properties of the callus into account. Regardless of this difference in fracture site and species and the fact that callus properties might vary when derived from CT data, the FEA results show that major changes from baseline are 
Table 2

Estimated marginal means (EMM) and their 95\% confidence intervals (CI) for the bone parameters at each visit and the percent change from baseline at visit 2, 3 and 4. ( $\mathrm{n}=18$ ).

\begin{tabular}{|c|c|c|c|c|c|c|c|c|c|c|c|c|c|c|c|}
\hline & & \multirow{2}{*}{\multicolumn{2}{|c|}{$\frac{\text { Visit } 1 / \text { baseline }}{(1.3 \pm 0.4 \text { weeks post-fx })}$}} & \multirow{2}{*}{\multicolumn{2}{|c|}{$\begin{array}{l}\text { Visit } 2 \\
(3.4 \pm 0.5 \text { weeks } \\
\text { post-fx })\end{array}$}} & \multirow{3}{*}{$\begin{array}{l}\text { Change from } \\
\text { baseline [\%] }\end{array}$} & \multirow{3}{*}{$\mathrm{p}$-value } & \multirow{2}{*}{\multicolumn{2}{|c|}{$\begin{array}{l}\text { Visit } 3 \\
(6.3 \pm 0.8 \text { weeks } \\
\text { post-fx })\end{array}$}} & \multirow{3}{*}{$\begin{array}{l}\text { Change from } \\
\text { baseline [\%] }\end{array}$} & \multirow{3}{*}{$\mathrm{p}$-value } & \multicolumn{2}{|l|}{ Visit 4} & \multirow{3}{*}{$\begin{array}{l}\text { Change from } \\
\text { baseline [\%] }\end{array}$} & \multirow{3}{*}{$\mathrm{p}$-value } \\
\hline & & & & & & & & & & & & \multicolumn{2}{|c|}{$(12.2 \pm 0.4$ weeks post- $\mathrm{fx})$} & & \\
\hline & & EMM & $95 \% \mathrm{Cl}$ & EMM & $95 \% \mathrm{Cl}$ & & & EMM & $95 \% \mathrm{Cl}$ & & & EMM & $95 \% \mathrm{Cl}$ & & \\
\hline \multicolumn{16}{|c|}{ Fracture side } \\
\hline Dtot & {$\left[\mathrm{mgHA} / \mathrm{cm}^{3}\right]$} & 232 & 204-259 & 243 & $218-268$ & 4.9 & 0.038 & 256 & $230-282$ & 10.5 & 0.010 & 253 & $227-278$ & 9.1 & 0.144 \\
\hline Dtrab & {$\left[\mathrm{mgHA} / \mathrm{cm}^{3}\right]$} & 146 & 131-161 & 160 & $146-174$ & 9.5 & 0.005 & 176 & 159-193 & 20.4 & 0.000 & 164 & $146-182$ & 12.1 & 0.153 \\
\hline Dcort & {$\left[\mathrm{mgHA} / \mathrm{cm}^{3}\right]$} & 646 & 588-705 & 628 & $570-685$ & -2.9 & 0.000 & 620 & $569-671$ & -4.1 & 0.040 & 613 & 567-659 & -5.2 & 0.052 \\
\hline Tb.N & {$[\mathrm{mm}-1]$} & 1.96 & $1.74-2.19$ & 2.01 & $1.78-2.24$ & 2.2 & 1.000 & 1.91 & $1.73-2.10$ & -2.5 & 1.000 & 1.67 & $1.46-1.89$ & -14.8 & 0.071 \\
\hline Tb.Th $^{a}$ & {$[\mathrm{~mm}]$} & 0.063 & $0.055-0.071$ & 0.068 & $0.060-0.076$ & 7.4 & 0.205 & 0.078 & $0.068-0.088$ & 23.0 & 0.001 & 0.082 & $0.073-0.092$ & 30.5 & 0.002 \\
\hline Tb.Sp ${ }^{a}$ & {$[\mathrm{~mm}]$} & 0.465 & $0.404-0.528$ & 0.442 & $0.396-0.490$ & -4.9 & 0.768 & 0.462 & $0.410-0.515$ & -0.7 & 1.000 & 0.545 & $0.461-0.635$ & 17.3 & 0.271 \\
\hline Ct.Th ${ }^{a}$ & {$[\mathrm{~mm}]$} & 0.39 & $0.29-0.49$ & 0.39 & $0.30-0.48$ & 0.7 & 1.000 & 0.41 & $0.32-0.51$ & 6.4 & 1.000 & 0.44 & $0.35-0.53$ & 12.9 & 0.390 \\
\hline Ct.Pm ${ }^{a}$ & {$[\mathrm{~mm}]$} & 87.1 & $79.0-95.9$ & 86.8 & $79.5-94.8$ & -0.3 & 1.000 & 84.7 & $78.2-91.7$ & -2.7 & 0.512 & 83.3 & $77.0-90.1$ & -4.3 & 0.090 \\
\hline Scomp & {$[\mathrm{kN} / \mathrm{mm}]$} & 16.5 & $12.4-20.6$ & 15.5 & $11.6-19.4$ & -6.2 & 0.527 & 16.7 & $12.4-20.9$ & 0.9 & 1.000 & 21.7 & $17.3-26.0$ & 31.3 & 0.008 \\
\hline Stors & {$[\mathrm{kNmm} / \mathrm{rad}]$} & 476 & $407-545$ & 438 & $373-502$ & -8.0 & 0.274 & 481 & $403-560$ & 1.1 & 1.000 & 626 & $551-700$ & 31.5 & 0.001 \\
\hline Sbend & {$[\mathrm{kNmm} / \mathrm{rad}]$} & 677 & $552-801$ & 614 & $498-730$ & -9.3 & 0.332 & 650 & $518-782$ & -4.0 & 1.000 & 888 & 759-1017 & 31.3 & 0.005 \\
\hline \multicolumn{16}{|c|}{ Contra-lateral side } \\
\hline Dtot & {$\left[\mathrm{mgHA} / \mathrm{cm}^{3}\right]$} & 247 & $206-288$ & \multirow{11}{*}{\multicolumn{8}{|c|}{ at the contra-lateral side no scans were made during the 2 nd and 3 rd visits }} & 248 & 207-289 & 0.4 & 0.780 \\
\hline Dtrab & {$\left[\mathrm{mgHA} / \mathrm{cm}^{3}\right]$} & 103 & $81-124$ & & & & & & & & & 100 & $79-122$ & -2.7 & 0.384 \\
\hline Dcort & {$[\mathrm{mgHA} / \mathrm{cm} 3]$} & 795 & $753-838$ & & & & & & & & & 798 & 753-844 & 0.4 & 0.525 \\
\hline Tb.N & {$\left[\mathrm{mm}^{-1}\right]$} & 1.46 & $1.24-1.69$ & & & & & & & & & 1.46 & $1.24-1.69$ & -0.1 & 0.939 \\
\hline Tb.Th & {$[\mathrm{mm}]$} & 0.058 & $0.052-0.064$ & & & & & & & & & 0.056 & $0.051-0.061$ & -2.7 & 0.138 \\
\hline Tb.Sp & {$[\mathrm{mm}]$} & 0.714 & $0.534-0.894$ & & & & & & & & & 0.710 & $0.549-0.871$ & -0.6 & 0.823 \\
\hline Ct.Th & {$[\mathrm{mm}]$} & 0.63 & $0.52-0.74$ & & & & & & & & & 0.64 & $0.52-0.76$ & 1.2 & 0.595 \\
\hline Ct.Pm & {$[\mathrm{mm}]$} & 69.6 & $66.3-72.9$ & & & & & & & & & 69.6 & $66.3-73.0$ & 0.0 & 0.946 \\
\hline Scomp & {$[\mathrm{kN} / \mathrm{mm}]$} & 67.2 & $56.8-77.6$ & & & & & & & & & 67.8 & $57.3-78.4$ & 1.0 & 0.487 \\
\hline Stors & {$[\mathrm{kNmm} / \mathrm{rad}]$} & 1470 & $1226-1713$ & & & & & & & & & 1484 & $1217-1752$ & 1.0 & 0.689 \\
\hline Sbend & {$[\mathrm{kNmm} / \mathrm{rad}]$} & 2533 & 2103-2963 & & & & & & & & & 2497 & $2060-2934$ & -1.4 & 0.458 \\
\hline
\end{tabular}

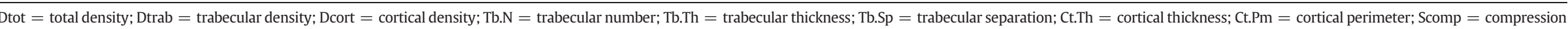
stiffness; Stors $=$ torsional stiffness; Sbend $=$ bending stiffness.

Estimated marginal means, 95\% confidence intervals and p-values were derived from a linear mixed effect model with time post-fracture as fixed effect.

${ }^{a}$ Not normally distributed across all visits and therefore the log-transform of the bone parameter was used in the linear mixed effect model. 


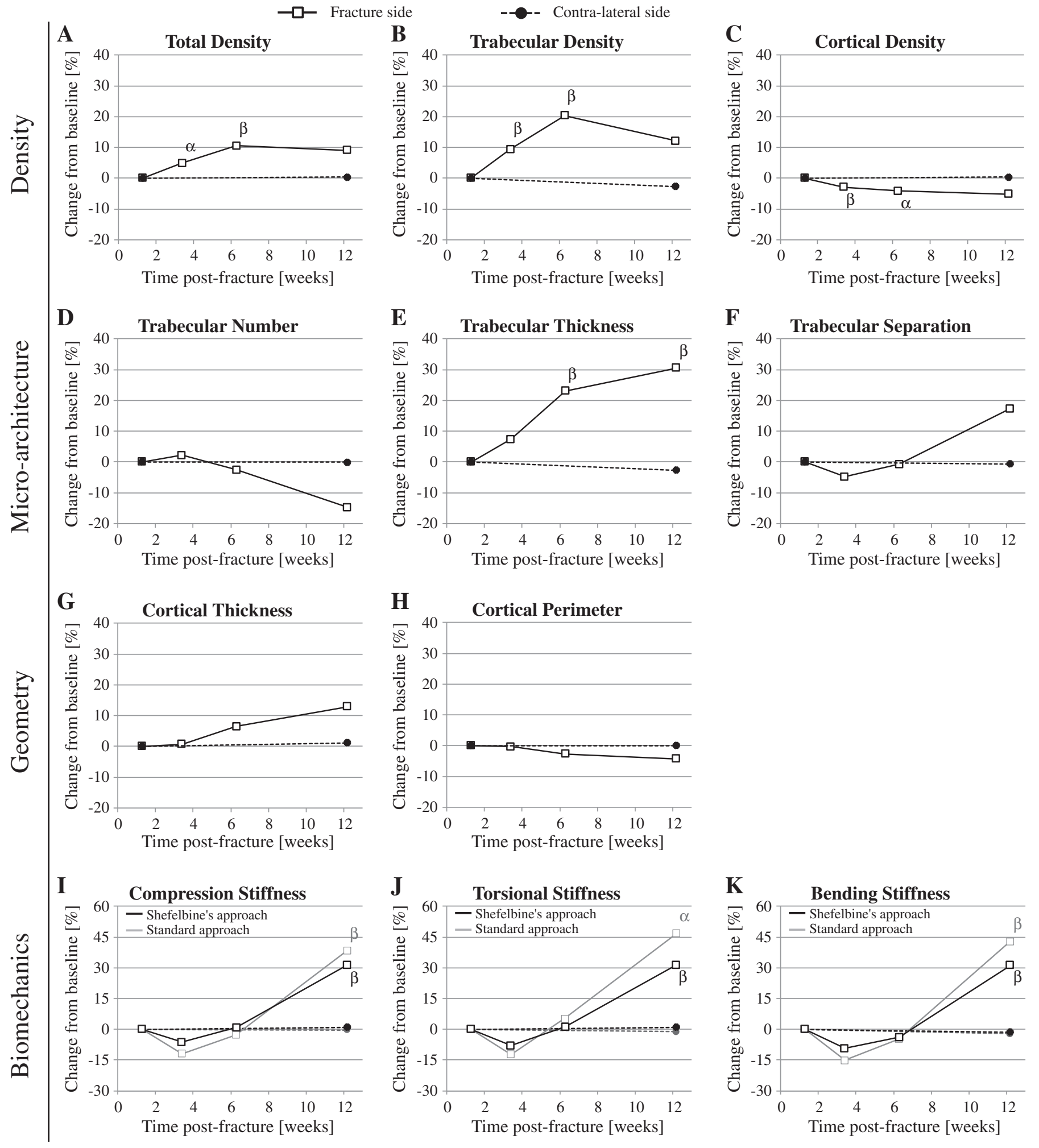

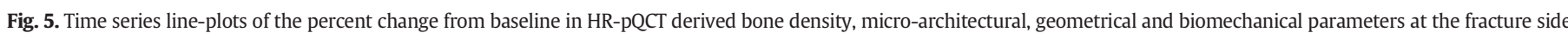
(white squares) and the contra-lateral side (black circles). ${ }^{\alpha}$ significantly different from baseline, $\mathrm{p}<0.05 .{ }^{\beta}$ significantly different from baseline, $\mathrm{p}<0.01$.

measured at 12 weeks post-fracture. Since a similar development in stiffness was calculated with the standard $\mu$ FEA approach, it might not make a big difference which approach is used. However, particular during the early stages of fracture healing we propose to incorporate the callus into the model and therefore use the method of Shefelbine et al. At later stages, when the callus becomes less prominent, the standard approach might suffice since the results acquired by both approaches converge to each other: at 12 weeks post-fracture the correlation between the compression stiffnesses calculated by the two methods is strong with an $\mathrm{R}^{2}$ of 0.81 .

The finding that both approaches indicate that the stiffness first tends to decrease and later increases could be due to the fact that we compared changes to the baseline case. It is possible that the stiffness at baseline is overestimated by the FEA because the imaging procedure 
Table 3

Correlations between the bone stiffness parameters and the PRWE score as well as the radiological state of consolidation.

\begin{tabular}{|c|c|c|c|c|}
\hline \multirow[t]{2}{*}{ Bone stiffness } & \multicolumn{2}{|c|}{ PRWE score } & \multicolumn{2}{|c|}{$\begin{array}{l}\text { Radiological state of } \\
\text { consolidation }\end{array}$} \\
\hline & rho & p-value & rho & p-value \\
\hline Scomp (Shefelbine FEA) & -0.282 & 0.029 & 0.437 & $<0.001$ \\
\hline Stors (Shefelbine FEA) & -0.291 & 0.024 & 0.353 & 0.006 \\
\hline Sbend (Shefelbine FEA) & -0.302 & 0.019 & 0.365 & 0.004 \\
\hline Scomp (standard FEA) & -0.327 & 0.011 & 0.500 & $<0.001$ \\
\hline Stors (standard FEA) & -0.322 & 0.012 & 0.441 & $<0.001$ \\
\hline Sbend (standard FEA) & -0.369 & 0.004 & 0.412 & 0.001 \\
\hline
\end{tabular}

Scomp $=$ compression stiffness; Stors $=$ torsional stiffness; Sbend $=$ bending stiffness; $\mathrm{FEA}=$ finite element analysis.

Correlations were calculated using Spearman's correlation coefficient (rho).

can identify touching trabeculae in the fractured region as connected. This might affect the standard $\mu$ FEA procedure more than Shefelbine's approach, hence this could explain why the final increase in compression stiffness calculated with the standard $\mu \mathrm{FEA}$ approach (38.4\%) is more pronounced than with the Shefelbine approach (31.1\%).

Interestingly the significant correlation between the PRWE score and the bone stiffness parameters suggests an association of this clinical parameter and HR-pQCT derived stiffness. This hypothesis is confirmed by Meyer et al. [39] who showed that early changes in torsional stiffness predict the clinical outcome at 12 weeks. When the first visit is not taken into account because of the suspected overestimation at this time-point, the Spearman's correlation coefficients are even higher for all stiffnesses.

\section{Limitations}

This study has several limitations. First, as was mentioned before, the interpretation of structural parameters is not the same as that for intact bone, in particular when considering parameters such as trabecular thickness. Although we find significant changes in the parameters, one should be careful with the interpretation of such changes. It has not been proven in this study that these changes are a meaningful representation of the bone consolidation during healing. The same holds for the results obtained from the $\mu \mathrm{FE}$ analyses. Although the higher resolution makes it possible to better detect the fracture, we presently cannot prove that the predicted changes in stiffness are realistic, nor can we prove that the results of $\mu \mathrm{FEA}$ are more accurate than those of continuum FEA based on clinical CT scans. A comparative study involving both continuum FE modeling and $\mu \mathrm{FE}$ modeling will be needed to further address these issues, but this was beyond the scope of the present paper.

Second, the region that was scanned at the contra-lateral side differed from the one at the fracture side. Thus we can only claim that nothing has changed at the contra-lateral side, but we cannot compare both sides to each other, which would have been very interesting. For example, it is unknown to what extent the stiffness at the fracture side has been restored to the pre-fracture stiffness. Since good correlations between the left and right radius has been reported [38], the stiffness at the contra-lateral side might be regarded as the pre-fracture stiffness. To be able to compare both sides, we recommend matching the location of the scanned volume at the contra-lateral side to the one at the fracture side in future studies.

Despite the correlation between the PRWE score and the bone stiffness, a third limitation of this study is that the two $\mu$ FEA methods that were applied are not validated in human distal radius fractures. It will be hard or even impossible to address this limitation adequately, i.e. experimentally measure bone strength in healing fractures in humans and compare it to the bone strength calculated from the $\mu \mathrm{FEA}$, since the validation would raise some serious ethical concerns. Alternatively, validation using an animal metaphyseal fracture healing model could be performed in the future.
Last, as can be seen in the 2D images and 3D models, we observed that the fracture healing process has not been fully completed at 12 weeks in most women. In future research, therefore, it is recommended to extend the follow-up period, e.g. to 24 weeks, to get a better end-point of the fracture healing process.

In conclusion, this study shows that it is possible to detect significant changes in HR-pQCT derived bone densitometric, micro-architectural and mechanical parameters during the first 12 weeks of healing of stable distal radius fractures. These results open a window to further explore the possibilities of HR-pQCT to monitor fracture healing in detail. It is recommended that future work should focus on the validation of the FEA approach and the development of new relevant parameters that benefit from the resolution of HR-pQCT.

\section{Disclosures}

This study was funded by the Weijerhorst Foundation (WH2).

B. van Rietbergen is a consultant for Scanco Medical AG

J.J. Arts is a board member of workgroup Biotechnology of the Dutch Orthopedic Association (NOV).

P.C. Willems is a board member of the Dutch Spine Society (association of spine surgeons).

\section{Acknowledgments}

The authors would like to thank Liesbeth Jutten and Margareth Winants from the Trialbureau of the department of Orthopedics for their efforts during the study.

\section{References}

[1] Tarantino U, Capone A, Planta M, D'Arienzo M, Letizia Mauro G, Impagliazzo A, et al. The incidence of hip, forearm, humeral, ankle, and vertebral fragility fractures in Italy: results from a 3-year multicenter study. Arthritis Res Ther 2010;12:R226.

[2] Jupiter J, Ring D, Weitzel P. Surgical treatment of redisplaced fractures of the distal radius in patients older than 60 years. J Hand Surg Am 2002;27:714-23.

[3] Rogachefsky R, Lipson S, Applegate BO, Ouellette EA, Savenor A, McAuliffe J. Treatment of severly comminute intra-articular fractures of the distal end of the raius by open reduction and combined internal and external fixation. J Bone Joint Surg Am 2001;83:509-19.

[4] Fernandez D, Geissler W. Treatment of displaced articular fractures of the radius. J Hand Surg Am 1991;16:375-84.

[5] Heim D, Stricker U, Rohrer G. Carpal tunnel syndrome after trauma. Swiss Surg 2002;8:15-20.

[6] Doetsch AM, Faber J, Lynnerup N, Watjen I, Bliddal H, Danneskiold-Samsoe B. The effect of calcium and vitamin D3 supplementation on the healing of the proximal humerus fracture: a randomized placebo-controlled study. Calcif Tissue Int 2004;75:183-8.

[7] Morgan EF, Mason ZD, Chien KB, Pfeiffer AJ, Barnes GL, Einhorn TA, et al. Microcomputed tomography assessment of fracture healing: relationships among callus structure, composition, and mechanical function. Bone 2009;44:335-44.

[8] Shefelbine SJ, Simon U, Claes L, Gold A, Gabet Y, Bab I, et al. Prediction of fracture callus mechanical properties using micro-CT images and voxel-based finite element analysis. Bone 2005;36:480-8.

[9] Augat P, Merk J, Genant H, Claes L. Quantitative assessment of experimental fracture repair by peripheral computed tomography. Calcif Tissue Int 1997;60:194-9.

[10] Grigoryan M, Lynch J, Fierlinger A, Guermazi A, Fan B, MacLean D, et al. Quantitative and qualitative assessment of closed fracture healing using computed tomography and conventional radiography. Acad Radiol 2003;10:1267-73.

[11] Liu XS, Zhang XH, Sekhon KK, Adams MF, McMahon DJ, Bilezikian JP, et al. Highresolution peripheral quantitative computed tomography can assess microstructural and mechanical properties of human distal tibial bone. J Bone Miner Res 2010;25:746-56

[12] Boutroy S, Bouxsein ML, Munoz F, Delmas PD. In vivo assessment of trabecular bone microarchitecture by high-resolution peripheral quantitative computed tomography. J Clin Endocrinol Metab 2005;90:6508-15.

[13] MacNeil JA, Boyd SK. Accuracy of high-resolution peripheral quantitative computed tomography for measurement of bone quality. Med Eng Phys 2007;29:1096-105.

[14] Macneil JA, Boyd SK. Bone strength at the distal radius can be estimated from highresolution peripheral quantitative computed tomography and the finite element method. Bone 2008;42:1203-13.

[15] Vilayphiou N, Boutroy S, Sornay-Rendu E, Van Rietbergen B, Munoz F, Delmas PD, et al. Finite element analysis performed on radius and tibia HR-pQCT images and fragility fractures at all sites in postmenopausal women. Bone 2010;46:1030-7.

[16] Dalzell N, Kaptoge S, Morris N, Berthier A, Koller B, Braak L, et al. Bone microarchitecture and determinants of strength in the radius and tibia: age-related 
changes in a population-based study of normal adults measured with highresolution pQCT. Osteoporos Int 2009;20:1683-94.

[17] Khosla S, Riggs BL, Atkinson EJ, Oberg AL, McDaniel LJ, Holets M, et al. Effects of sex and age on bone microstructure at the ultradistal radius: a population-based noninvasive in vivo assessment. J Bone Miner Res 2006;21:124-31.

[18] Bacchetta J, Boutroy S, Vilayphiou N, Juillard L, Guebre-Egziabher F, Rognant N, et al. Early impairment of trabecular microarchitecture assessed with HR-pQCT in patients with stage II-IV chronic kidney disease. J Bone Miner Res 2010;25:849-57.

[19] Romme EA, Rutten EP, Geusens P, de Jong JJ, van Rietbergen B, Smeenk FW, et al. Bone stiffness and failure load are related with clinical parameters in men with chronic obstructive pulmonary disease. J Bone Miner Res 2013;28:2186-93.

[20] Burghardt AJ, Kazakia GJ, Sode M, de Papp AE, Link TM, Majumdar S. A longitudinal HR-pQCT study of alendronate treatment in postmenopausal women with low bone density: relations among density, cortical and trabecular microarchitecture, biomechanics, and bone turnover. J Bone Miner Res 2010;25:2558-71.

[21] Chapurlat RD, Laroche M, Thomas T, Rouanet S, Delmas PD, de Vernejoul MC. Effect of oral monthly ibandronate on bone microarchitecture in women with osteopenia-a randomized placebo-controlled trial. Osteoporos Int 2013;24:311-20.

[22] Rizzoli R, Chapurlat RD, Laroche JM, Krieg MA, Thomas T, Frieling I, et al. Effects of strontium ranelate and alendronate on bone microstructure in women with osteoporosis. Results of a 2-year study. Osteoporos Int 2012;23:305-15.

[23] Seeman E, Chapurlat R, Cheung A, Felsenberg D, La-Roche M, Reeve J, et al. Risedronate reduces microstructural deterioration of cortical bone accompanying menopause. Osteoporos Int 2010;21(Suppl. 1):S9.

[24] Mueller TL, Stauber M, Kohler T, Eckstein F, Muller R, van Lenthe GH. Non-invasive bone competence analysis by high-resolution PQCT: an in vitro reproducibility study on structural and mechanical properties at the human radius. Bone 2009;44:364-71.

[25] Pialat JB, Burghardt AJ, Sode M, Link TM, Majumdar S. Visual grading of motion induced image degradation in high resolution peripheral computed tomography: impact of image quality on measures of bone density and micro-architecture. Bone 2012;50:111-8.

[26] Laib A, Hauselmann HJ, Ruegsegger P. In vivo high resolution 3D-QCT of the human forearm. Technol Health Care 1998;6:329-37.

[27] Laib A, Rüegsegger P. Comparison of structure extraction methods for in vivo trabecular bone measurements. Comput Med Imaging Graph 1999;23:69-74.
[28] Hilderbrand T, Laib A, Müller R, Dequeker J, Rüegsegger P. Direct three-dimensional morhpometric analysis of human cancellous bone: microstructural data from spine, femur, iliac crest, and calcaneus. J Bone Miner Res 1999;17:1167-74.

[29] Pistoia W, van Rietbergen B, Lochmuller EM, Lill CA, Eckstein F, Ruegsegger P. Estimation of distal radius failure load with micro-finite element analysis models based on three-dimensional peripheral quantitative computed tomography images. Bone 2002;30:842-8.

[30] Chevalley T, Bonjour JP, van Rietbergen B, Ferrari S, Rizzoli R. Fractures during childhood and adolescence in healthy boys: relation with bone mass, microstructure, and strength. J Clin Endocrinol Metab 2011;96:3134-42.

[31] MacDermid JC. Development of a scale for patient rating of wrist pain and disability J Hand Ther 1996;9:178-83.

[32] Brink SM, Voskamp EG, Houpt P, Emmelot CH. Psychometric properties of the Patient Rated Wrist/Hand Evaluation-Dutch Language Version (PRWH/E-DLV). Hand Surg Eur Vol 2009;34:556-7.

[33] Kristiansen TK, Ryaby JP, McCabe J, Frey JJ, Roe LR. Accelerated healing of distal radia fractures with the use of specific, low-intensity ultrasound. A multicenter, prospective, randomized, double-blind, placebo-controlled study. J Bone Joint Surg Am 1997;79:961-73.

[34] Aspenberg P, Sandberg O. Distal radial fractures heal by direct woven bone formation. Acta Orthop 2013;84:297-300.

[35] Uhthoff HK, Rahn BA. Healing patterns of metaphyseal fractures. Clin Orthop Relat Res 1981:295-303.

[36] Sevitt S. The healing of fractures of the lower end of the radius. A histological and angiographic study. J Bone Joint Surg Br 1971;53:519-31.

[37] Tanck E, Homminga J, van Lenthe GH, Huiskes R. Increase in bone volume fraction precedes architectural adaptation in growing bone. Bone 2001;28:650-4.

[38] Groll O, Lochmuller EM, Bachmeier M, Willnecker J, Eckstein F. Precision and intersite correlation of bone densitometry at the radius, tibia and femur with peripheral quantitative CT. Skeletal Radiol 1999;28:696-702.

[39] Meyer U, de Jong JJ, Bours SG, Keszei AP, Arts JJ, Brink PR, et al. Early Changes in Bone Density, Micro-Architecture, Bone Resorption and Inflammation Predict the Clinical Outcome 12 Weeks After Conservatively Treated Distal Radius Fractures: An Exploratory Study. J Bone Miner Res 2014 Advance online publication. http://dx.doi.org/10. 1002/jbmr.2225. 